\title{
Polymorphism of asymmetric catalysts based on amphiphilic lipopeptides in solution
}

Article

Accepted Version

Pelin, J. N. B. D., Edwards-Gayle, C. J. C., Aguilar, A. M., Kaur, A., Hamley, I. W. and Alves, W. A. (2020) Polymorphism of asymmetric catalysts based on amphiphilic lipopeptides in solution. Soft Matter, 16 (19). pp. 4615-4624. ISSN 1744-683X doi: https://doi.org/10.1039/D0SM00245C Available at https://centaur.reading.ac.uk/90611/

It is advisable to refer to the publisher's version if you intend to cite from the work. See Guidance on citing.

Published version at: http://dx.doi.org/10.1039/D0SM00245C

To link to this article DOI: http://dx.doi.org/10.1039/D0SM00245C

Publisher: Royal Society of Chemistry

All outputs in CentAUR are protected by Intellectual Property Rights law, including copyright law. Copyright and IPR is retained by the creators or other copyright holders. Terms and conditions for use of this material are defined in the End User Agreement.

www.reading.ac.uk/centaur 
Central Archive at the University of Reading

Reading's research outputs online 


\section{Polymorphism of asymmetric catalysts based on amphiphilic lipopeptides in solution}

Juliane N. B. D. Pelin, ${ }^{[a, b]}$ Charlotte J. C. Edwards-Gayle, ${ }^{[b]}$ Andrea M. Aguilar, ${ }^{[c]}$ Amanpreet Kaur, ${ }^{[b]}$ Ian W. Hamley, ${ }^{[b], *}$ Wendel A. Alves ${ }^{[a], *}$

${ }^{[a]}$ Centro de Ciências Naturais e Humanas, Universidade Federal do ABC, 09210-580, Santo André, Brazil.

${ }^{[b]}$ Department of Chemistry, University of Reading, Reading RG6 6AD, United Kingdom.

${ }^{[c]}$ Instituto de Ciências Ambientais, Químicas e Farmacêuticas, Universidade Federal de São Paulo, Diadema, 09972-270, Brazil.

* Authors for correspondence. wendel.alves@ufabc.edu.br, I.W.Hamley@ reading.ac.uk 


\begin{abstract}
The self-assembly of model [P]RWG lipopeptides (P: L-proline, R: L-arginine, W: Ltryptophan, G: L-glycine), containing one or two aliphatic octadecyl $\left(\mathrm{C}_{18}\right)$ chains in water and cyclohexanone / water solutions was examined. The self-assembly of mixtures of these RWG and PRWG lipopeptides was also investigated. These materials presented a similar critical aggregation concentration of $\sim 4.0 \times 10^{-4} \mathrm{wt} \%$ and were characterized by unordered secondary structures with some $\beta$-sheet content. TEM and cryo-TEM revealed the presence of mainly nanotape structures with micelles observed for systems rich in $\mathrm{PRWG}\left(\mathrm{C}_{18} \mathrm{H}_{37}\right)$. Analysis of detailed SAXS form factor measurements revealed the presence of bilayers 3 $-4 \mathrm{~nm}$ thick while the PRWG $\left(\mathrm{C}_{18} \mathrm{H}_{37}\right)$ micelles have a core radius of approximately $3 \mathrm{~nm}$, and a shell thickness of $2 \mathrm{~nm}$. For the cyclohexanone / water systems polymorphs containing cluster aggregates (with radius of $0.25 \mathrm{~nm}$ to $0.50 \mathrm{~nm}$ ) and some elongated structures (with radius of $5.7 \mathrm{~nm}$ to $26.1 \mathrm{~nm}$ ) were seen. Longer structures were formed with the increase of the proline-containing lipopeptide content. The catalytic activity of these peptides was assessed using a model nitro-aldol reaction. The concentration of water in the reaction system influenced the conversion, higher content promoted better efficiency for the water systems, but the opposite was observed for the cyclohexanone / water samples.
\end{abstract}




\section{INTRODUCTION}

Self-assembled amphiphilic oligopeptides systems have attracted strong interest due to their potential for bionanotechnological applications for new materials and in the development of diagnostic and therapeutic strategies where protein and peptide aggregation is associated with disease. ${ }^{[1-4]}$ Peptide amphiphiles (PAs) are structures based on hydrophobic blocks, such as lipid chains, and bioactive peptides, which correspond to the hydrophilic part. ${ }^{[5-8]}$ Among several promising uses, we can highlight the development of sensing devices, ${ }^{[9]}$ molecular carriers, ${ }^{[10,11]}$ and bioelectronics. ${ }^{[12]}$ Many advantages especially the fast synthesis, functionalization capabilities, and relatively low cost confirm the potential of these systems. ${ }^{[1,2,13-15]}$

One of the great advantages of amphiphilic peptides as models for studies on aggregation processes is their capability to self-assemble into a rich variety of morphologies. ${ }^{[16]}$ Various self-assembled structures including nanofibers, nanotapes and micelles, have been reported. ${ }^{[6-8,15,17-19]}$ These systems are thus excellent models for the formulation of biomimetic materials and for establishing interfaces with biological systems. The self-assembly into distinct morphologies depends on concentration, $\mathrm{pH}$ and temperature, among other parameters. Sequences containing free L-proline (P) coupled with long carbon aliphatic chains can act as organocatalysts for direct aldol reactions in water. Many works used lipidated proline derivatives in asymmetric aldol reactions and observed that the conversion and stereoselectivity are parameters that depend on the selfassembled structure in solution. ${ }^{[20-26]}$ Changes in peptide sequence lead to new modes of self-assembly, through a combination of different supramolecular interactions, such as $\pi$ stacking, electrostatic and hydrogen bonding. ${ }^{[27,28]}$

Organocatalysts incorporating L-proline residues have been demonstrated to be successful as asymmetric catalysts for a wide range of synthetic reactions. ${ }^{[29]}$ Proline-based peptides with attached hydrophobic chains have been found to catalyze aldol reactions in reaction mixtures containing both water and organic solvents. ${ }^{[25]}$ Aldol reactions combine two carbonyl compounds to form a new $\mathrm{C}-\mathrm{C}$ bond, to produce a compound containing a $\beta$ hydroxy carbonyl group, ${ }^{[30,31]}$ found in living organisms with unusual pharmacological activities. The reactions mediated by proline have high enantioselectivity, which can be explained by its ability to promote the formation of highly organized transition states via hydrogen bonds. In all these reactions, proton transfer from the amine or carboxylic acid of the proline residue to the forming alkoxide or imide is essential for charge stabilization and to facilitate the formation of the $\mathrm{C}-\mathrm{C}$ bond in the transition state. ${ }^{[32]}$ Because of this 
unique characteristic as an organocatalyst, many studies have evaluated the application of proline in several asymmetric reactions, including Michael and Mannich reactions, and aldol reactions. ${ }^{[33-38]}$

However, despite the high efficiency and selectivity observed in reactions that are catalyzed by proline, some characteristics can be improved, including the large required amount of catalyst, excess reagents, low catalyst solubility in an organic reaction medium, and extended reaction time. Many of the aldol reactions involving L-proline are carried out in organic solvents such as DMSO and chloroform which are harmful and environmentally unfavorable. ${ }^{[27]}$ As a result, there is a current drive to overcome this by replacing the solvents with a green solvent such as water. The use of water is also attractive for promoting self-assembly via hydrophobic interactions and hydrogen bonding.

Therefore, to address these problems and to enhance the catalytic performance of proline, a large number of organocatalysts derived from proline have been developed, ${ }^{\text {[33-37] }}$ but few works are showing the effect of the self-assembled nanostructure on the catalytic activity of such systems. Previous results showed that conformational changes are important parameters that modify the yield of asymmetric aldol reactions since the packing factor, radius and morphology of these nanostructures can influence the reagents' availability to interact with the substrate in solution. ${ }^{[28]}$

A lipidated peptide with a $\mathrm{C}_{16}$ (hexadecyl, palmitoyl) chain attached at the C-terminus and a proline based head group (PRW- $\mathrm{C}_{16}$ ), was found to be an excellent catalyst for aldol reactions performed in water, with very good stereoselectivity and conversion rates. ${ }^{[27]}$ The lipidated peptide self-assembled into spherical micelles above a critical aggregation concentration ( $\mathrm{cac}$ ), and the self-assembled structures were the driving force of the catalysis since poor results were obtained in the absence of lipidated assembles. It showed better catalytic efficiency in aqueous media, by comparison with its performance in organic media (neat cyclohexanone), since the micelle seems to provide an environment that enhances catalysis. ${ }^{[27]}$ In contrast, poor results were obtained in the absence of the lipopeptide assemblies. In another example, Miravet, Escuder et al. reported examples of aldol reactions catalyzed by L-proline-derived peptides that form organo-gels, ${ }^{[21]}$ or hydrogels. ${ }^{[39]}$

Another parameter that can influence the self-assembly is the size of the lipid chain attached to the peptide sequence. Increasing the number of carbon atoms, an enhancement of the hydrophobicity is observed and, consequently, different polymorphs can be structured. Here we study the self-assembly of the lipopeptides, based on L-arginine, L- 
tryptophan, L-proline and L-glycine attached to an aliphatic chain containing eighteen carbons, and their efficiency as catalysts in aldol reactions. The molecular structures are presented in Figure 1. The glycine amino acid was used as a spacer between the peptide and the lipid chain. Also, the effect of including a free proline residue was monitored, since it is well known to increase the aldol reaction efficiency. ${ }^{[40]}$

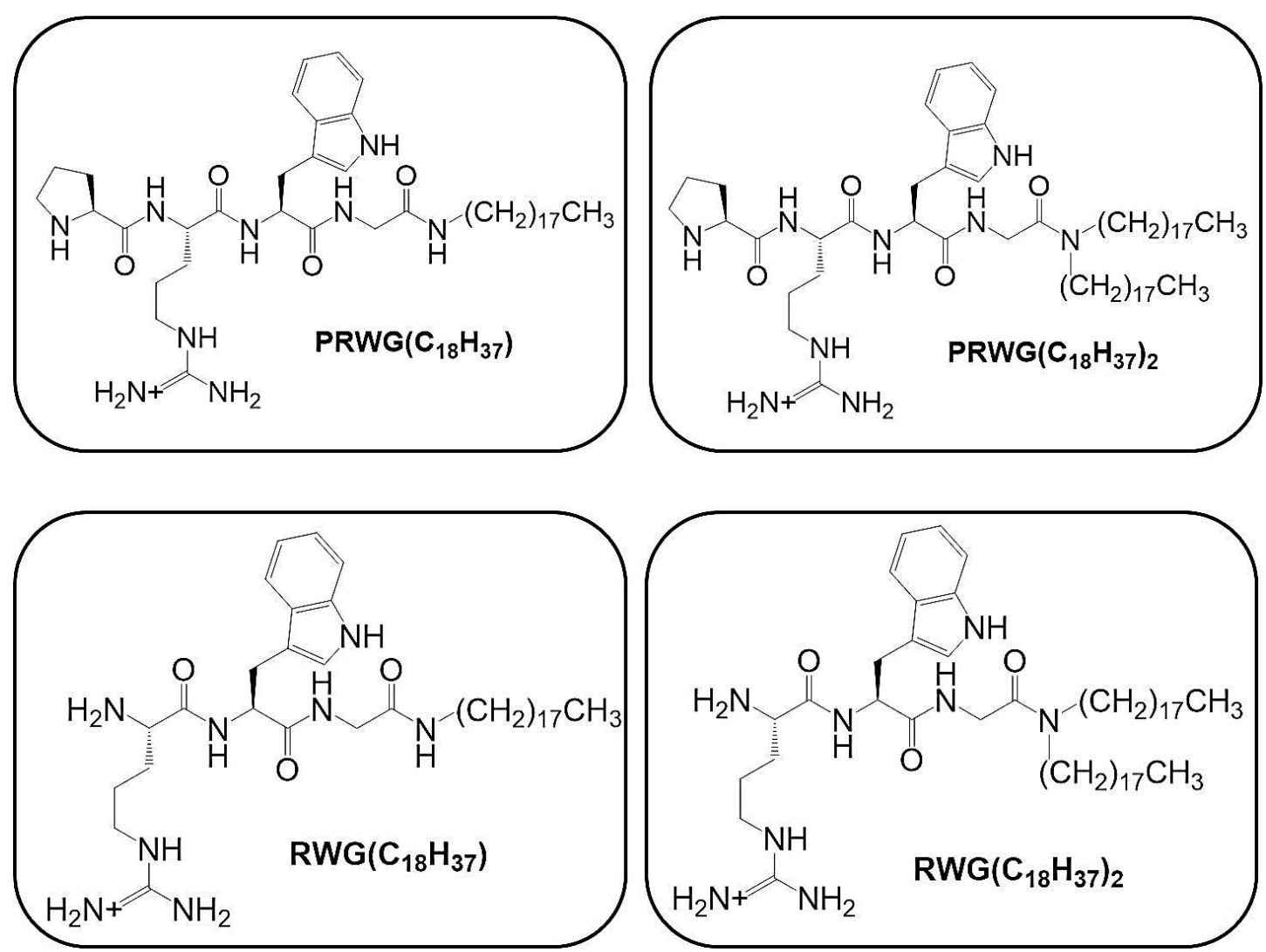

Figure 1. Molecular structures of $\operatorname{PRWG}\left(\mathrm{C}_{18} \mathrm{H}_{37}\right), \quad \operatorname{PRWG}\left(\mathrm{C}_{18} \mathrm{H}_{37}\right)_{2}, \quad \mathrm{RWG}\left(\mathrm{C}_{18} \mathrm{H}_{37}\right)$, and RWG $\left(\mathrm{C}_{18} \mathrm{H}_{37}\right)_{2}$ lipopeptides.

We investigate the conformation and self-assembly of the lipopeptides, presented in Figure 1, in the absence and presence of proline, using water and cyclohexanone / water mixture as solvents, using a combination of microscopy, spectroscopy and scattering techniques. To the best of our knowledge, the effect of mixing lipopeptides with different alkyl chain lengths on morphology and biocatalytic behavior has not previously been examined. Besides, asymmetric direct aldol reactions mediated by cyclohexanone and $p$ nitrobenzaldehyde were made to evaluate their efficiency as catalysts.

\section{MATERIALS AND METHODS}


Materials. The lipopeptides were synthesised by Peptide Synthetics, UK; with purity evaluated by HPLC > $95.0 \%$ : The molecular weight of each sequence was determined by mass spectrometry: $\mathrm{RWG}\left(\mathrm{C}_{18} \mathrm{H}_{37}\right) 668.9 \mathrm{~g} \mathrm{~mol}^{-1}$ (expected: $\left.668.6 \mathrm{~g} \mathrm{~mol}^{-1}\right), \mathrm{RWG}\left(\mathrm{C}_{18} \mathrm{H}_{37}\right)_{2}$ $921.3 \mathrm{~g} \mathrm{~mol}^{-1}$ (expected: $921.4 \mathrm{~g} \mathrm{~mol}^{-1}$ ), PRWG(C $\left.\mathrm{C}_{18} \mathrm{H}_{37}\right) 765.7 \mathrm{~g} \mathrm{~mol}^{-1}$ (expected: $766.1 \mathrm{~g}$ $\left.\mathrm{mol}^{-1}\right)$ and PRWG $\left(\mathrm{C}_{18} \mathrm{H}_{37}\right)_{2} 1018.3 \mathrm{~g} \mathrm{~mol}^{-1}$ (expected: $1018.5 \mathrm{~g} \mathrm{~mol}^{-1}$ ). The mass spectra chromatograms can be seen in Figure S1.

Systems preparation. Firstly, the self-assembly process was monitored considering the mixtures of the lipopeptides and the influence of their ratio amount in water (W) solutions. In this case, mixtures of $\mathrm{PRWG}\left(\mathrm{C}_{18} \mathrm{H}_{37}\right) / \mathrm{RWG}\left(\mathrm{C}_{18} \mathrm{H}_{37}\right)\left[\mathrm{P}_{1} \mathrm{R}_{1}\right]$ and $\mathrm{PRWG}\left(\mathrm{C}_{18} \mathrm{H}_{37}\right)_{2} /$ $\mathrm{RWG}\left(\mathrm{C}_{18} \mathrm{H}_{37}\right)_{2}\left[\mathrm{P}_{2} \mathrm{R}_{2}\right]$ were selected with proportions $v / v$ :

\begin{tabular}{|c|c|c|c|c|c|}
\hline Samples & $\begin{array}{c}\operatorname{PRWG}\left(\mathrm{C}_{18} \mathrm{H}_{37}\right) \\
(v)\end{array}$ & $\begin{array}{c}\mathrm{RWG}\left(\mathrm{C}_{18} \mathrm{H}_{37}\right) \\
(v)\end{array}$ & Samples & $\begin{array}{c}\text { PRWG }\left(\mathrm{C}_{18} \mathrm{H}_{37}\right)_{2} \\
(v)\end{array}$ & $\begin{array}{c}\mathbf{R W G}\left(\mathrm{C}_{18} \mathrm{H}_{37}\right)_{2} \\
(v)\end{array}$ \\
\hline $\mathbf{P}_{1} \mathbf{R}_{1} \mathrm{~W} 1$ & 0 & 1 & $\mathbf{P}_{2} \mathbf{R}_{2} \mathbf{W} 1$ & 0 & 1 \\
\hline$P_{1} R_{1} W 2$ & 0.3 & 0.7 & $\mathbf{P}_{2} \mathbf{R}_{2} \mathbf{W} 2$ & 0.3 & 0.7 \\
\hline $\mathbf{P}_{1} \mathbf{R}_{\mathbf{1}} \mathbf{W} 3$ & 0.5 & 0.5 & $\mathbf{P}_{2} \mathbf{R}_{2} \mathbf{W} 3$ & 0.5 & 0.5 \\
\hline $\mathbf{P}_{1} \mathbf{R}_{1} \mathbf{W} 4$ & 0.7 & 0.3 & $\mathbf{P}_{2} \mathbf{R}_{2} W 4$ & 0.7 & 0.3 \\
\hline$P_{1} R_{1} W 5$ & 1 & 0 & $P_{2} R_{2} W 5$ & 1 & 0 \\
\hline
\end{tabular}

After that, the effect of the solvent on the polymorphism was evaluated, changing the samples solvent for a combination of 5:1 cyclohexanone / water (C). Mixtures solutions were prepared with proportions $v / v$ :

\begin{tabular}{|c|c|c|c|c|c|}
\hline Samples & $\begin{array}{c}\operatorname{PRWG}\left(\mathrm{C}_{18} \mathrm{H}_{37}\right) \\
(v)\end{array}$ & $\begin{array}{c}\mathbf{R W G}\left(\mathbf{C}_{18} \mathbf{H}_{37}\right) \\
(v)\end{array}$ & Samples & $\begin{array}{c}\text { PRWG }\left(\mathrm{C}_{18} \mathrm{H}_{37}\right)_{2} \\
(v)\end{array}$ & $\begin{array}{c}\mathrm{RWG}\left(\mathrm{C}_{18} \mathrm{H}_{37}\right)_{2} \\
(v)\end{array}$ \\
\hline$P_{1} R_{1} C_{1}$ & 0 & 1 & $\mathbf{P}_{2} \mathrm{R}_{2} \mathrm{C} 1$ & 0 & 1 \\
\hline$P_{1} R_{1} C_{2}$ & 0.3 & 0.7 & $\mathrm{P}_{2} \mathrm{R}_{2} \mathrm{C} 2$ & 0.3 & 0.7 \\
\hline$P_{1} R_{1}$ C 3 & 0.5 & 0.5 & $\mathbf{P}_{2} \mathbf{R}_{2} \mathrm{C} 3$ & 0.5 & 0.5 \\
\hline$P_{1} R_{1} C_{4}$ & 0.7 & 0.3 & $\mathbf{P}_{2} R_{2} C_{4}$ & 0.7 & 0.3 \\
\hline$P_{1} R_{1} C_{5}$ & 1 & 0 & $\mathbf{P}_{2} R_{2} C_{5}$ & 1 & 0 \\
\hline
\end{tabular}

The water addition was made only after the peptides powder solubilized completely in cyclohexanone. 
All solutions were prepared with water purified by the Direct-Q System, Millipore, with resistivity of $18.2 \mathrm{~m} \Omega \mathrm{cm}^{-1}$ (at $25{ }^{\circ} \mathrm{C}$ ) and TOC below $10 \mathrm{ppb}$. Cyclohexanone was purchased from Sigma Aldrich.

Fluorescence Spectroscopy. Fluorescence spectra were recorded with a Varian Cary Eclipse fluorescence spectrometer with samples in $4 \mathrm{~mm}$ inner quartz cuvettes. ANS assays were performed using $1.0 \times 10^{-7}$ to $0.1 \mathrm{wt} \%$ peptide, in $2.0 \times 10^{-3} \mathrm{wt} \% 8$-anilino-1napthalenesulfonic acid (ANS) solution. The samples were excited at $\lambda_{\mathrm{ex}}=356 \mathrm{~nm}$, and the fluorescence emission was measured for $\lambda=400-650 \mathrm{~nm}$. Water assays were also performed using the same peptide concentration, using the tryptophan emission band $\left(\lambda_{\text {em }}\right.$ 330-350 nm). The samples were excited at $\lambda_{\mathrm{ex}}=280 \mathrm{~nm}$, and the fluorescence emission was measured for $\lambda=300-460 \mathrm{~nm}$.

Circular Dichroism (CD). CD spectra were obtained using a Chirascan spectropolarimeter (Applied Photophysics, UK). Solutions containing $0.1 \mathrm{wt} \%$ of peptide were scanned at $20{ }^{\circ} \mathrm{C}$ in a quartz cuvette with thickness of $0.01 \mathrm{~mm}$. The spectra were recorded with absorbance $\mathrm{A}<2$ at any measured point, considering $0.5 \mathrm{~nm}$ step, $1 \mathrm{~nm}$ bandwidth and $1 \mathrm{~s}$ collection time per step. A water background CD signal was used to subtract the baseline from the experimental data.

Transmission electron microscopy (TEM). TEM was performed on a JEOL 2100Plus, instrument operating at $200 \mathrm{kV}$. Copper grids (Agar Scientific, UK) $5.0 \mathrm{~mm}$ in diameter and $10 \mu \mathrm{m}$ thick, coated with carbon film, were used. The samples were stained with $1 \mathrm{wt} \%$ uranyl acetate (Sigma-Aldrich, UK), and left to dry at room temperature.

Cryogenic Transmission Electron Microscopy (Cryo-TEM). Cryo-TEM images of the systems (1-10) were carried out using the JEOL JEM-3200FSC instrument, operating at $200 \mathrm{kV}$. A bright-field mode and zero loss energy filtering (omega type) with a slit width of $20 \mathrm{eV}$ was used. Micrographs were recorded using a Gatan Ultrascan 4000 CCD camera, at $-187{ }^{\circ} \mathrm{C}$. Vitrified specimens were prepared using an automated FEI Vitrobot device using Quantifoil 3.5/1 holey carbon copper grids with a hole size of $3.5 \mu \mathrm{m}$. The grids were plasma cleaned using a Gatan Solarus 9500 plasma cleaner and then transferred into the environmental chamber of an FEI Vitrobot at room temperature and $100 \%$ humidity. Thereafter, $3 \mu \mathrm{L}$ of the sample solution was applied on the grid and it was blotted twice for $5 \mathrm{~s}$ and then vitrified in a 1:1 mixture of liquid ethane and propane at a temperature of -180 
${ }^{\circ} \mathrm{C}$. The grids with vitrified sample solution were maintained at liquid nitrogen temperature and then cryo-transferred to the microscope.

Small-Angle X-ray Scattering (SAXS). SAXS experiments were performed on the bioSAXS beamline B21 at the Diamond light source, U.K. Solutions containing $1 \mathrm{wt} \%$ peptide were loaded in PCR tubes in an automated sample changer. For the cyclohexanone / water samples, $100 \mu \mathrm{L}$ of $1.0 \mathrm{wt} \%$ systems were measured on a capillary with a thickness of $0.01 \mathrm{~mm}$, length of $80 \mathrm{~mm}$ and outside of $1.5 \mathrm{~mm}$. Data was collected using a Dectris PILATUS $2 \mathrm{M}$ detector at a fixed camera length of $3.9 \mathrm{~m}$ with a wavelength $\lambda=1 \AA$. Data are presented as a function of $q=4 \pi \sin \theta / \lambda$, where $2 \theta$ is the scattering angle.

Aldol reactions in water. Asymmetric aldol reactions using cyclohexanone and $p$ nitrobenzaldehyde were chosen to evaluate the efficiency of the lipopeptides as catalysts. The reactions were performed using different catalyst amounts of 5 and 20 mol\%. Two methodologies were tested: from the powder peptides and from the solutions $\mathbf{P}_{\mathbf{1}} \mathbf{R}_{\mathbf{1}} \mathbf{C}$ (1-5) and $\mathbf{P}_{2} \mathbf{R}_{2} \mathbf{C}$ (1-5). Considering the first methodology, $20.2 \mu \mathrm{L}$ of cyclohexanone $(0.19$ mmol, 12 equivalents) was mixed with $1.0 \mathrm{mg}$ of catalyst $(0.81 \mu \mathrm{mol})$ and then $2.45 \mathrm{mg}$ of $p$-nitrobenzaldehyde (1.6 $\mu \mathrm{mol}, 1$ equivalent) and $40.4 \mu \mathrm{L}$ of water $(2 \mathrm{x}$ cyclohexanone volume) were added, for $5 \mathrm{~mol} \%$ catalyst reaction. The solutions were stirred at room temperature for three days and the mixtures were extracted with ethyl acetate four times, via centrifugation at $4000 \mathrm{rpm}$ for $5 \mathrm{~min}$. After, the organic phase was removed on a rotary evaporator and the samples were solubilized using deuterated chloroform. NMR measurements using a $\left({ }^{1} \mathrm{H}\right)$ Bruker Ultrashield Plus 400 instrument were performed at 400 MHz. The yield and diastereomer anti:syn ratio were calculated using the NMR spectra obtained, for which tetramethylsilane (TMS) was used as a reference.

For the second methodology, for the $5 \mathrm{~mol} \%$ catalyst, $2.45 \mathrm{mg}$ of $p$-nitrobenzaldehyde (1.6 $\mu$ mol, 1 equivalent) was added in $60.6 \mu \mathrm{L}$ of systems $\mathbf{P}_{\mathbf{1}} \mathbf{R}_{\mathbf{1}} \mathbf{C}$ (1-5) and $\mathbf{P}_{\mathbf{2}} \mathbf{R}_{\mathbf{2}} \mathbf{C}$ (1-5), containing cyclohexanone / water mixture $(5: 1, v / v)$, respectively. The same proceeding used in the first methodology was performed to obtain and analyze the aldol product.

\section{RESULTS}


Fluorescence assays were made to determine the $c a c$ of the lipopeptides in water, which is the minimum concentration at they aggregate in solution. Firstly, intrinsic tryptophan fluorescence was probed, which revealed a $c a c$ of $(3.4 \pm 0.5) \times 10^{-4} \mathrm{wt} \%$ for all systems. Figure 2 shows the fluorescence intensity as a function of the peptide concentrations. As can be seen in Figure S2, the same cac value was observed for solutions with ANS (except $\left.\operatorname{PRWG}\left(\mathrm{C}_{18} \mathrm{H}_{37}\right)_{2}\right)$, a probe that is well known to promote interaction with hydrophobic binding sites, enhancing the fluorescence signal. ${ }^{[41,42]}$ The original fluorescence emission spectra are shown in Figures S3 and S4. It is surprising that the cac does not seem to be sensitive to the different numbers of alkyl chains in the mono- and di-alkyl chain functionalized molecules. This may be related to differences in the aggregation state of the lipopeptides above the $c a c$, as discussed below.
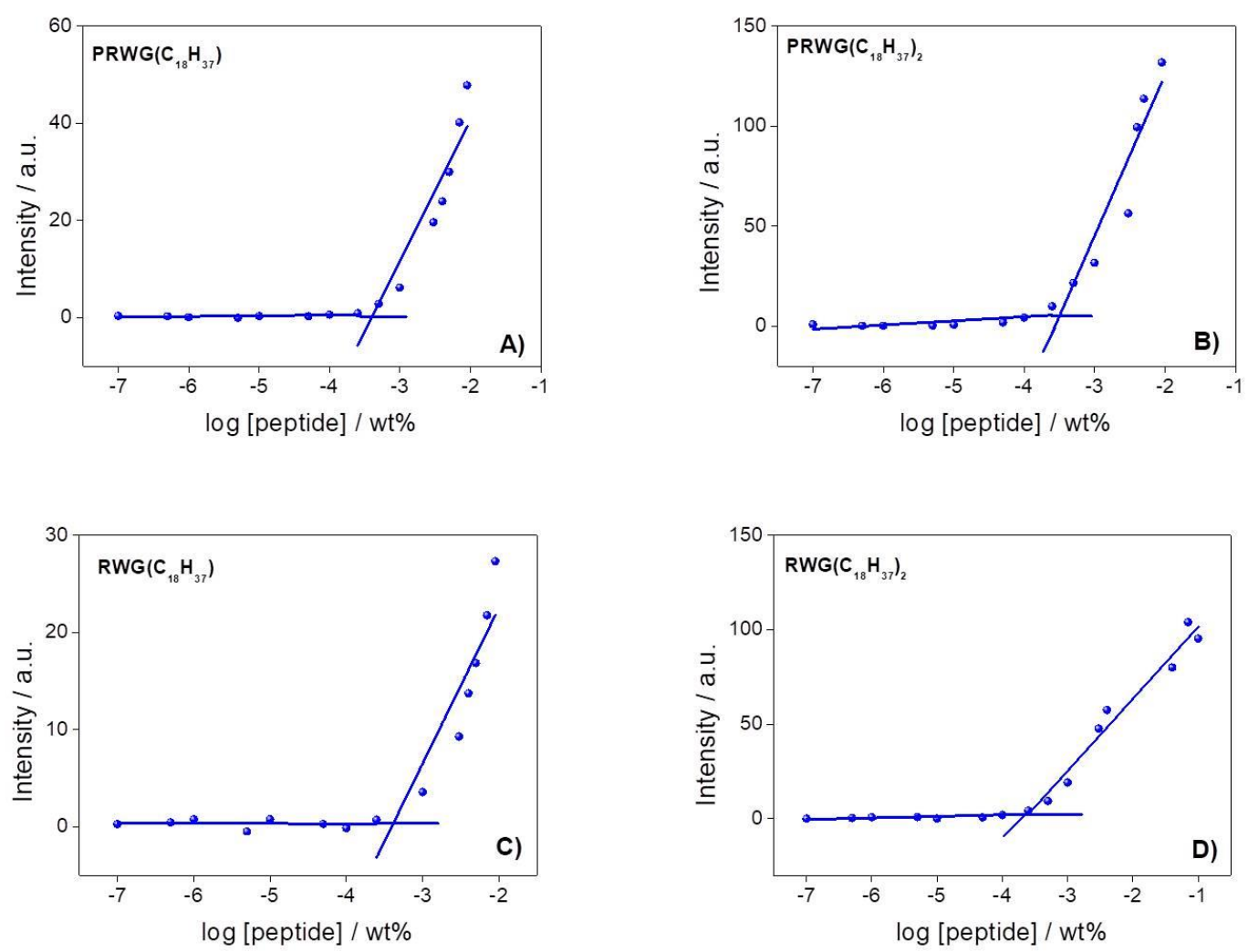

Figure 2. Intrinsic tryptophan fluorescence intensity as a function of $\left.A) \operatorname{PRWG}\left(\mathrm{C}_{18} \mathrm{H}_{37}\right), B\right)$ $\left.\operatorname{PRWG}\left(\mathrm{C}_{18} \mathrm{H}_{37}\right)_{2}, \mathrm{C}\right) \mathrm{RWG}\left(\mathrm{C}_{18} \mathrm{H}_{37}\right)$ and D) $\mathrm{RWG}\left(\mathrm{C}_{18} \mathrm{H}_{37}\right)_{2}$ lipopeptides concentration.

CD spectra were measured to determine peptide conformation in the self-assembled lipopeptide solutions. As the systems $\mathbf{P}_{\mathbf{1}} \mathbf{R}_{\mathbf{1}} \mathbf{C}$ (1-5) and $\mathbf{P}_{\mathbf{2}} \mathbf{R}_{\mathbf{2}} \mathbf{C}$ (1-5) showed too high absorbance due to the cyclohexanone solvent, they are not considered further. Figure 3 
shows the spectra for the samples $\mathbf{P}_{\mathbf{1}} \mathbf{R}_{\mathbf{1}} \mathbf{W}$ (1-5) and $\mathbf{P}_{\mathbf{2}} \mathbf{R}_{\mathbf{2}} \mathbf{W}$ (1-5). The systems $\left(\mathbf{P}_{\mathbf{1}} \mathbf{R}_{\mathbf{1}} \mathbf{W} \mathbf{1}\right)$ and $\left(\mathbf{P}_{\mathbf{1}} \mathbf{R}_{\mathbf{1}} \mathbf{W} 2\right)$ presented, in the UV region, the $\pi \rightarrow \pi^{*}$ transitions, characterized by two positive bands: at $205 \mathrm{~nm}$ and $201 \mathrm{~nm}$, respectively, and at $220 \mathrm{~nm}$ and $225 \mathrm{~nm}$, which correspond to the overlap of the indole and amide groups, dominated by the chiral signal of tryptophan residue. ${ }^{[43]}$ The other samples $\left(\mathbf{P}_{\mathbf{1}} \mathbf{R}_{\mathbf{1}} \mathbf{W}\right.$ 3-5) only presented a maximum located between $228 \mathrm{~nm}$ and $230 \mathrm{~nm}$, correlated with the amide signal and possibly due to tryptophan $\pi$-stacking interactions, suggesting the formation of week $\beta$-sheet structures. The $\mathbf{P}_{\mathbf{2}} \mathbf{R}_{\mathbf{2}} \mathbf{W} 1-5$ systems were characterized by a broad negative band at 210-214 $\mathrm{nm}$ and a positive band at $228 \mathrm{~nm}$, associated with proline. ${ }^{[44-46]}$ The differences in the CD spectra for the lipopeptides may be correlated with differences the morphology, to be discussed.
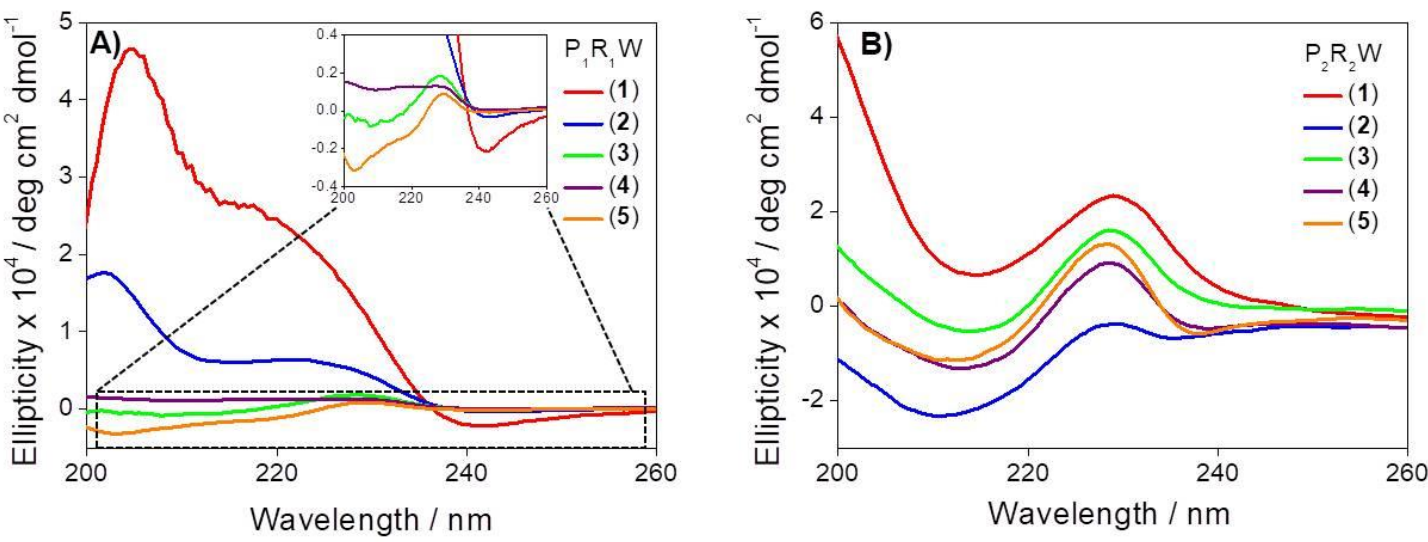

Figure 3. CD spectra of $0.1 \mathrm{wt} \%$ aqueous solutions of lipopeptides A) $\left(\mathbf{P}_{1} \mathbf{R}_{\mathbf{1}} \mathbf{W} \mathbf{1 - 5}\right)$ and B) $\left(\mathbf{P}_{2} \mathbf{R}_{\mathbf{2}} \mathbf{W}\right.$ 1-5).

TEM was used to identify self-assembled structures above the $c a c$. The images shown in Fig.4 revealed the coexistence of self-assembled nanotape and bilayer structures for samples $\mathbf{P}_{\mathbf{1}} \mathbf{R}_{\mathbf{1}} \mathbf{W}$ (1-3) and spherical micelles or micelle clusters for $\mathbf{P}_{\mathbf{1}} \mathbf{R}_{\mathbf{1}} \mathbf{W}$ (4-5). CryoTEM images, presented in Figure S5, show the formation of thin cylinders, with a diameter lower than $50 \mathrm{~nm}$, corroborating with CD results, and bilayers with approximately $200 \mathrm{~nm}$ in diameter. TEM images shown in Fig.5 of the $\mathbf{P}_{\mathbf{2}} \mathbf{R}_{\mathbf{2}} \mathbf{W}$ (1-3) systems showed bilayers with a diameter of $200 \mathrm{~nm}$ to $300 \mathrm{~nm}$ and small nanotapes. Polydisperse nanosheets were observed for the $\mathbf{P}_{\mathbf{2}} \mathbf{R}_{\mathbf{2}} \mathbf{W}$ (4-5) samples. 

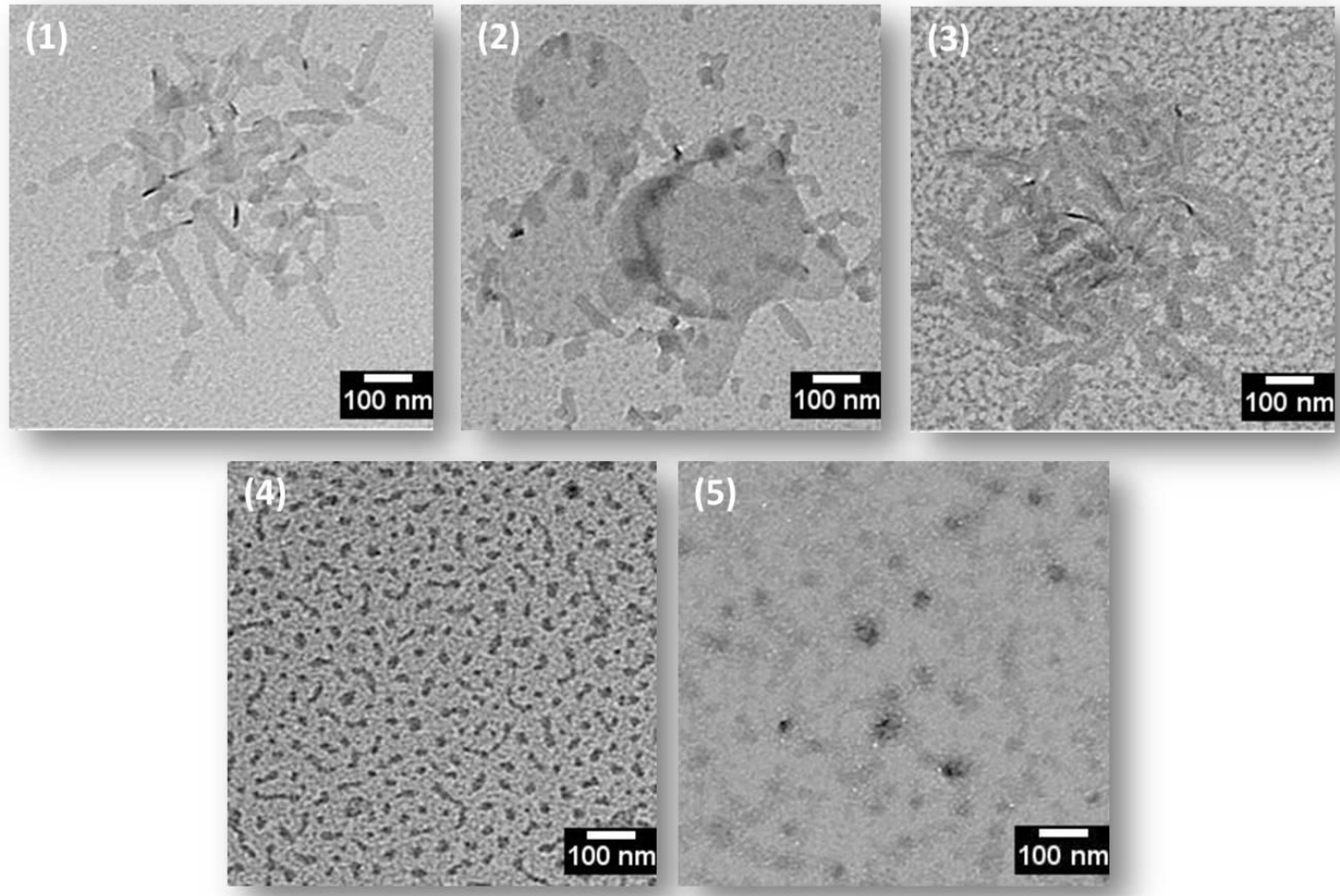

Figure 4. TEM images of 1 wt $\%$ solutions of $\mathbf{P}_{\mathbf{1}} \mathbf{R}_{\mathbf{1}} \mathbf{W}(\mathbf{1}-\mathbf{5})$.
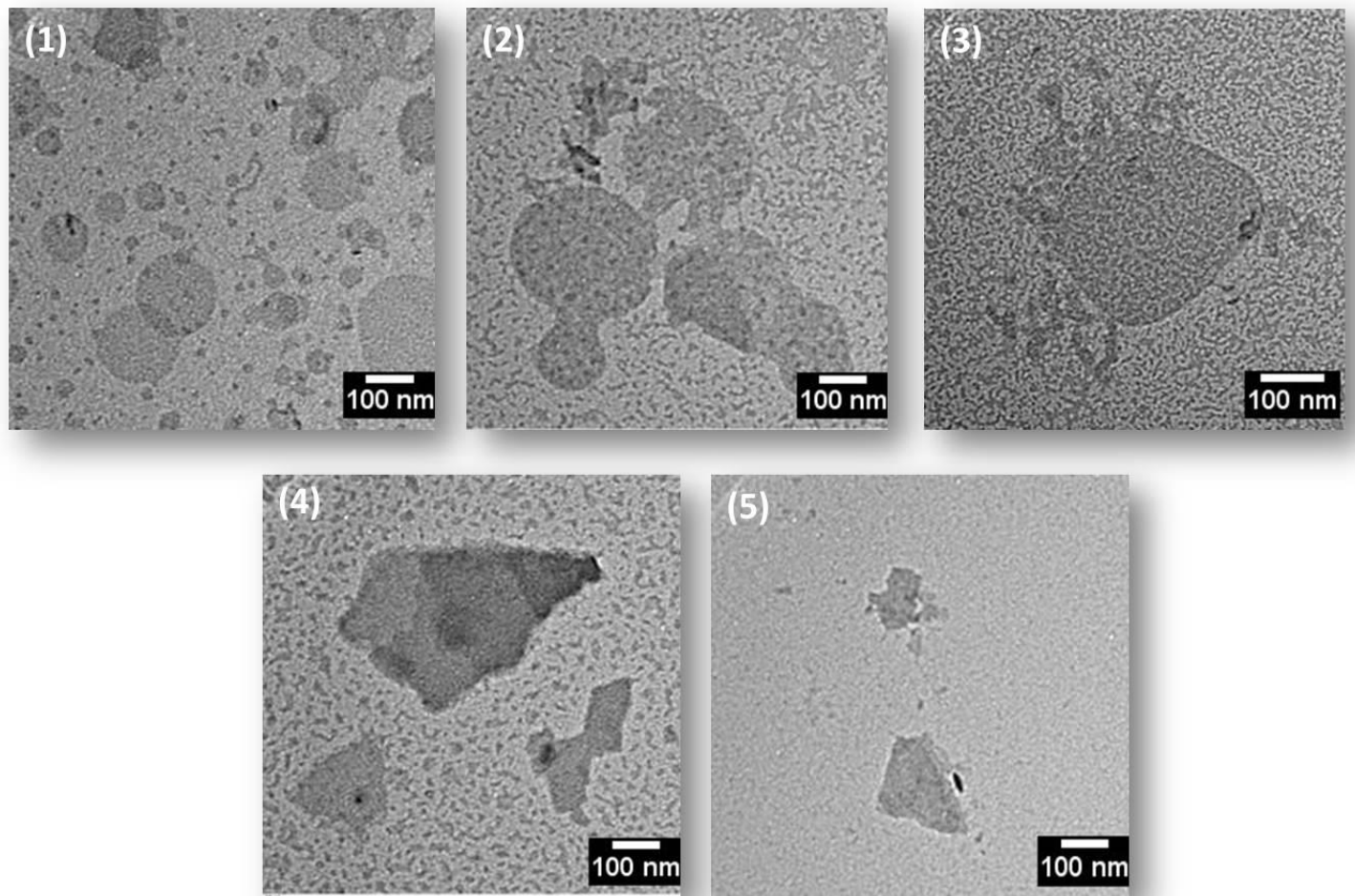

Figure 5. TEM images of $1 \mathrm{wt} \%$ solutions of $\mathbf{P}_{\mathbf{2}} \mathbf{R}_{\mathbf{2}} \mathbf{W}$ (1-5). 
Figure 6 presents the SAXS measurements, showing more details about the nanoscale shape and dimensions. SASFit ${ }^{[47]}$ software was used to fit the SAXS curves, and the red curves, presented in Figure 6, represent the adjusted form factors. All systems, except $\mathbf{P}_{\mathbf{1}} \mathbf{R}_{\mathbf{1}} \mathbf{W}$ 5, were provided considering a bilayer Gaussian form factor (with a fixed diameter planar object of $500 \mathrm{~nm}$ ) and a Gaussian size distribution. This form factor, based on that used for lipid bilayers, ${ }^{[48]}$ has been used successfully to fit the form factor of lipopeptide nanotape and nanosheet structures. ${ }^{[49,50]}$ The form factor for samples $\mathbf{P}_{\mathbf{1}} \mathbf{R}_{\mathbf{1}} \mathbf{W} \mathbf{4}$ and $\mathbf{P}_{\mathbf{1}} \mathbf{R}_{\mathbf{1}} \mathbf{W}$ 5 shows a different shape with a flat intensity profile at low $q$ and sharp oscillations at high $q$. These are characteristics of the form factor of core-shell particles (i.e., micelles), so the scattering data were fitted to a core-shell form factor model, using Gaussian size distribution $\left(\sigma_{\mathrm{R}}\right)$ of the radius. Table 1 summarizes the fitted parameters.

The parameters in Table 1 show a decrease of the micelles thickness $(t)$, in the systems $\mathbf{P}_{\mathbf{1}} \mathbf{R}_{\mathbf{1}} \mathbf{W}$ (1-5), with the increase of PRWG $\left(\mathrm{C}_{18} \mathrm{H}_{37}\right)$ content, from $3.6 \mathrm{~nm}$ for sample $\mathbf{P}_{\mathbf{1}} \mathbf{R}_{\mathbf{1}} \mathbf{W}$ $\mathbf{1}$ to $2.2 \mathrm{~nm}$ for $\mathbf{P}_{\mathbf{1}} \mathbf{R}_{\mathbf{1}} \mathbf{W}$ 5. The core electron density in the bilayer structures becomes more negative with increasing $\mathrm{PRWG}\left(\mathrm{C}_{18} \mathrm{H}_{37}\right)$ content, indicating a more electron-dense core structure (the same trend was also observed for the spherical micelles, comparing $\mathbf{P}_{\mathbf{1}} \mathbf{R}_{\mathbf{1}} \mathbf{W}$ 4 and $P_{1} R_{1} W 5$ ). 


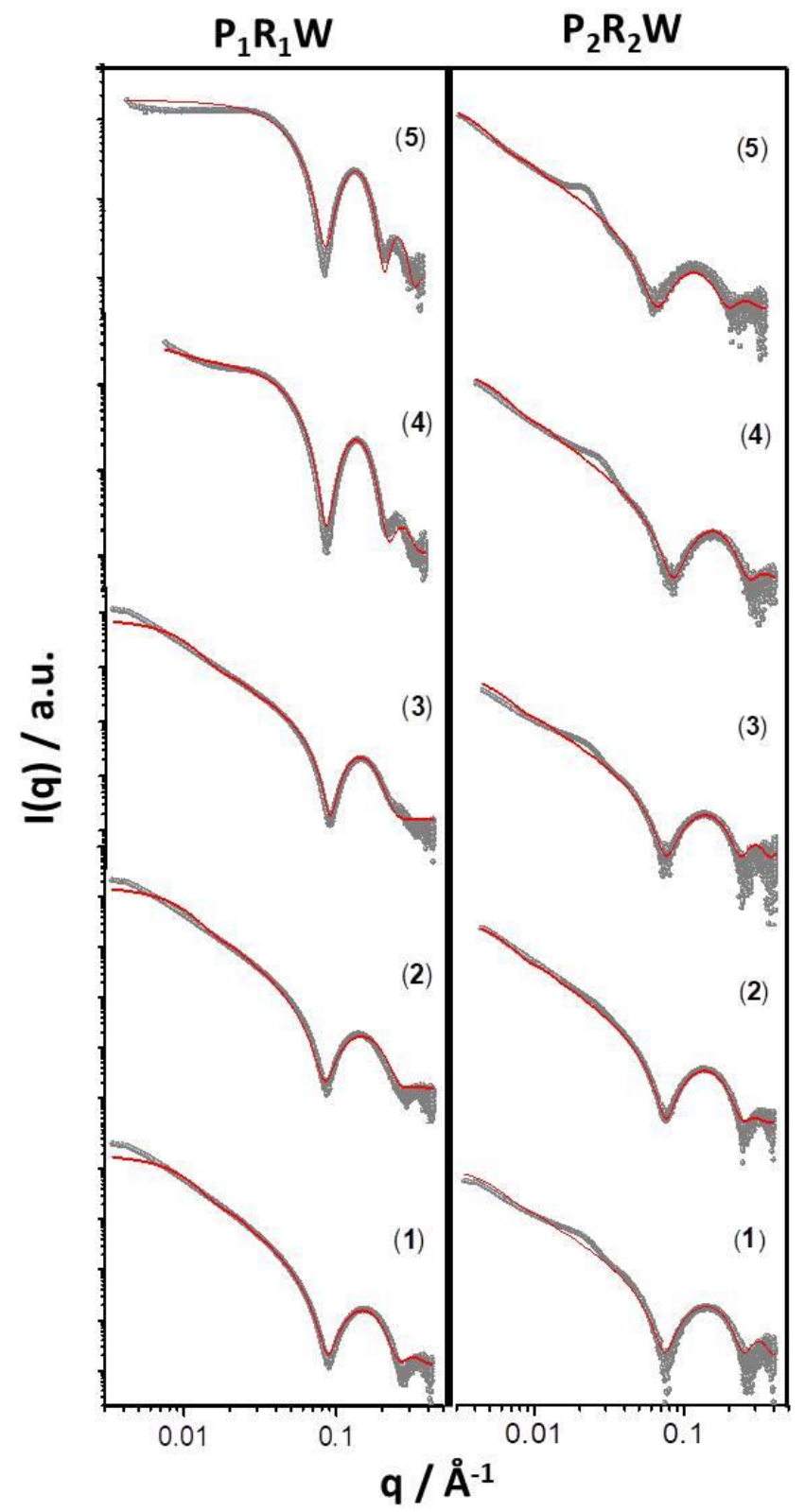

Figure 6. SAXS data (grey points) of systems $\mathbf{P}_{\mathbf{1}} \mathbf{R}_{\mathbf{1}} \mathbf{W}$ (1-5) and $\mathbf{P}_{2} \mathbf{R}_{\mathbf{2}} \mathbf{W}$ (1-5) in $\mathrm{pH}$ native. Model fits (red line) using the model described in the text.

An opposite effect was observed for the samples $\mathbf{P}_{\mathbf{2}} \mathbf{R}_{\mathbf{2}} \mathbf{W}$ (1-5), which presented a slight increase in the thickness when the PRWG $\left(\mathrm{C}_{18} \mathrm{H}_{37}\right)_{2}$ was enhanced. The trend in core scattering density is also opposite to that observed for systems $\mathbf{P}_{\mathbf{1}} \mathbf{R}_{\mathbf{1}} \mathbf{W}$ (1-5), suggesting that the two lipid chains in $\operatorname{PRWG}\left(\mathrm{C}_{16} \mathrm{H}_{37}\right)_{2}$ are less tightly packed. 
Table 1. Summary of the model parameters obtained from the fitting procedure of SAXS data for the lipopeptide water solutions.*

\begin{tabular}{c|cccccc|ccccc}
\hline Samples & \multicolumn{7}{|c|}{ Bilayer Gauss* } & \multicolumn{5}{c}{ Spherical shell i } \\
\hline & $\mathbf{t}$ & $\begin{array}{c}\boldsymbol{\sigma}_{\mathbf{t}} \\
(\mathbf{n m})\end{array}$ & $\begin{array}{c}\boldsymbol{\sigma}_{\text {out }} \\
(\mathbf{n m})\end{array}$ & $\mathbf{b}_{\text {out }}$ & $\begin{array}{c}\boldsymbol{\sigma}_{\text {core }} \\
(\mathbf{n m})\end{array}$ & $\mathbf{b}_{\text {core }}$ & $\begin{array}{c}\mathbf{R}_{\mathbf{1}} \\
(\mathbf{n m})\end{array}$ & $\begin{array}{c}\mathbf{R}_{2} \\
(\mathbf{n m})\end{array}$ & $\begin{array}{c}\boldsymbol{\sigma}_{\mathbf{R}} \\
(\mathbf{n m})\end{array}$ & $\boldsymbol{\mu}$ & $\mathbf{\eta}$ \\
\hline $\mathbf{P}_{\mathbf{1}} \mathbf{R}_{\mathbf{1}} \mathbf{W}$ & & & & & & & & & & & \\
$(\mathbf{1})$ & 3.6 & 0.24 & 0.5 & $1.0 \times 10^{-6}$ & 1.1 & $1.0 \times 10^{-8}$ & - & - & - & - & - \\
$(\mathbf{2})$ & 3.3 & 0.18 & 0.5 & $1.0 \times 10^{-6}$ & 1.2 & $-2.3 \times 10^{-7}$ & - & - & - & - & - \\
$(\mathbf{3})$ & 2.8 & 0.03 & 1.1 & $2.4 \times 10^{-6}$ & 1.9 & $-2.6 \times 10^{-6}$ & - & - & - & - & - \\
$(\mathbf{4})$ & 2.6 & 0.04 & 1.5 & $2.0 \times 10^{-6}$ & 2.1 & $-2.9 \times 10^{-6}$ & 3.4 & 2.0 & 0.5 & -1.2 & $3.5 \times 10^{-6}$ \\
$(\mathbf{5})$ & - & - & - & - & - & - & 3.1 & 2.2 & 0.4 & -0.8 & $5.2 \times 10^{-6}$ \\
\hline $\mathbf{P}_{2} \mathbf{R}_{2} \mathbf{W}$ & & & & & & & & & & & \\
$(\mathbf{1})$ & 3.8 & 0.20 & 1.4 & $8.1 \times 10^{-7}$ & 0.5 & $-6.1 \times 10^{-7}$ & - & - & - & - & - \\
$(\mathbf{2})$ & 3.6 & 0.19 & 5.2 & $3.1 \times 10^{-7}$ & 1.2 & $-5.2 \times 10^{-7}$ & - & - & - & - & - \\
$(\mathbf{3})$ & 3.8 & 0.19 & 1.5 & $6.7 \times 10^{-7}$ & 0.9 & $-2.1 \times 10^{-7}$ & - & - & - & - & - \\
$(\mathbf{4})$ & 3.8 & 0.14 & 4.5 & $2.8 \times 10^{-7}$ & 2.2 & $-4.9 \times 10^{-8}$ & - & - & - & - & - \\
$(\mathbf{5})$ & 4.0 & 0.12 & 3.3 & $1.9 \times 10^{-7}$ & 4.9 & $-6.9 \times 10^{-9}$ & - & - & - & - & - \\
\hline
\end{tabular}

*The diameter of the bilayer structures (D) was fixed at $500 \mathrm{~nm}$, and $\sigma_{\mathrm{t}}$ corresponds to the thickness dispersity.

Considering the self-assembly process of the cyclohexanone/water mixtures, TEM images of the samples $\mathbf{P}_{\mathbf{1}} \mathbf{R}_{\mathbf{1}} \mathbf{C}$ (1-5) and $\mathbf{P}_{\mathbf{2}} \mathbf{R}_{\mathbf{2}} \mathbf{C}$ (1-5), (Figures S6 and S7) showed the formation of polydisperse aggregates. The lipopeptides, with one lipid chain, form more ordered and defined structures in comparison with the aggregates of the two lipid chain lipopeptides. They were characterized by different assembly/aggregation properties in suspension: globular $\left(\mathbf{P}_{2} \mathbf{R}_{2} \mathbf{C} \mathbf{1}\right.$ and $\mathbf{P}_{2} \mathbf{R}_{\mathbf{2}} \mathbf{C}$ 5), with a radius of approximately $25 \mathrm{~nm}$, or elongated ( $\mathbf{P}_{2} \mathbf{R}_{2} \mathbf{C} 2, \mathbf{P}_{2} \mathbf{R}_{2} \mathbf{C} 3$ and $\left.\mathbf{P}_{2} \mathbf{R}_{2} \mathbf{C} 4\right)$.

SAXS data for systems $\mathbf{P}_{\mathbf{1}} \mathbf{R}_{\mathbf{1}} \mathbf{C}$ (1-5) and $\mathbf{P}_{\mathbf{2}} \mathbf{R}_{\mathbf{2}} \mathbf{C}$ (1-5) were fitted using a combination of two form factors (mass fractal Gaussian and long cylindrical shell), allowing for the presence of the clusters and fibril structures observed in the TEM images. Figure 7 presents the fitted curves, and Table 2 summarizes the fit parameters.

The parameters in Table 2 indicate a gradual increase of the fractal cluster radius ( $\left.R^{\prime}\right)$ with increasing proline-lipopeptide content in the systems, from $0.37 \mathrm{~nm}$ for $\mathbf{P}_{\mathbf{1}} \mathbf{R}_{\mathbf{1}} \mathbf{C} \mathbf{1}$ to $0.5 \mathrm{~nm}$ for $\mathbf{P}_{\mathbf{1}} \mathbf{R}_{\mathbf{1}} \mathbf{C}$ 5; and from $0.25 \mathrm{~nm}$ for $\mathbf{P}_{\mathbf{2}} \mathbf{R}_{\mathbf{2}} \mathbf{C} \mathbf{1}$ to $0.40 \mathrm{~nm}$ for $\mathbf{P}_{\mathbf{2}} \mathbf{R}_{\mathbf{2}} \mathbf{C} \mathbf{5}$. However, for both peptides systems, a decrease of fractal dimension (D) was seen as the proline content increases, suggesting the presence of more compact clusters. The same effect was observed for the cylinder contribution. An increase of the cylinder radius (R) and the cylinders shell thickness $(\Delta \mathrm{R})$ was seen as the proline-lipopeptide content increases, suggesting large 
structures being formed. Considering the (electron) scattering length density, a higher electron density contrast for the shell ( $n_{\text {shell }}$ ) was observed for the systems $\mathbf{P}_{\mathbf{1}} \mathbf{R}_{\mathbf{1}} \mathbf{C}$ (1-5) and at the core ( $\eta_{\text {core }}$ ) for the systems $\mathbf{P}_{\mathbf{2}} \mathbf{R}_{\mathbf{2}} \mathbf{C}(\mathbf{1 - 4})$, these results prove smaller aggregates being formed for the $\mathbf{P}_{\mathbf{2}} \mathbf{R}_{\mathbf{2}} \mathbf{C}$ in comparison with the $\mathbf{P}_{\mathbf{1}} \mathbf{R}_{\mathbf{1}} \mathbf{C}$ samples. Only $\mathbf{P}_{\mathbf{2}} \mathbf{R}_{\mathbf{2}} \mathbf{C} \mathbf{5}$ had a slight electron density at the shell, which can be associated with a higher structure dimension.

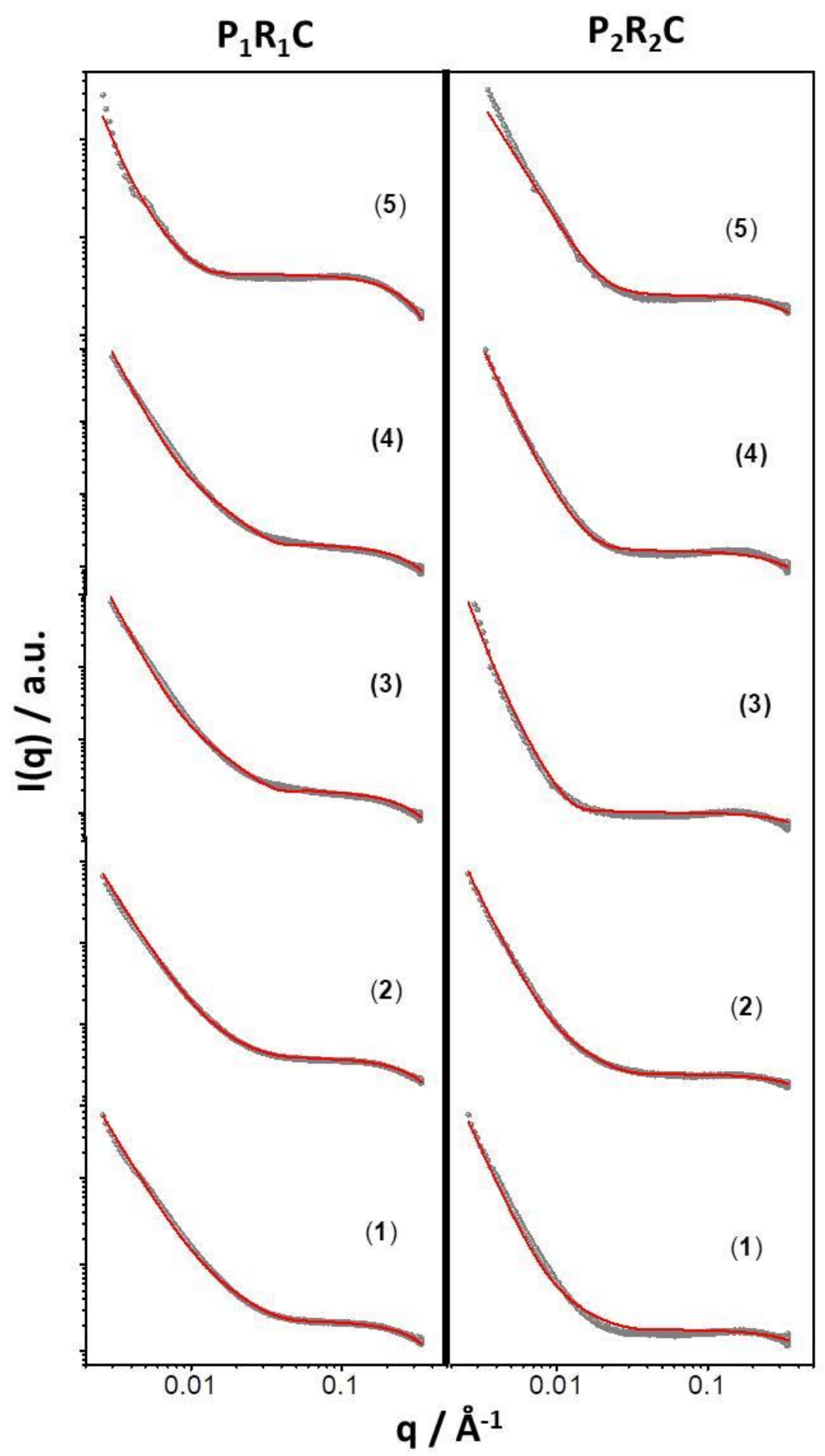


Figure 7. SAXS data (grey points) of systems $\mathbf{P}_{\mathbf{1}} \mathbf{R}_{\mathbf{1}} \mathbf{C}$ (1-5) and $\mathbf{P}_{\mathbf{2}} \mathbf{R}_{\mathbf{2}} \mathbf{C}$ (1-5) in $\mathrm{pH}$ native. Model fits (red line) using the model described in the text.

Table 2. Summary of the model parameters obtained from the fitting procedure of SAXS data for the systems $\mathbf{P}_{\mathbf{1}} \mathbf{R}_{\mathbf{1}} \mathbf{C}$ (1-5) and $\mathbf{P}_{\mathbf{2}} \mathbf{R}_{\mathbf{2}} \mathbf{C}(\mathbf{1 - 5})$ in $\mathrm{pH}$ native.*

\begin{tabular}{|c|c|c|c|c|c|c|c|c|}
\hline \multirow[t]{2}{*}{ ] } & \multicolumn{3}{|c|}{$\begin{array}{c}\text { Mass Fractal } \\
\text { Gaussian }\end{array}$} & \multicolumn{5}{|c|}{ Long Cylindrical Shell } \\
\hline & $\begin{array}{c}\mathbf{R}^{\prime} \\
(\mathbf{n m})\end{array}$ & $\begin{array}{c}\sigma_{\mathrm{R}} \\
(\mathrm{nm}) \\
\end{array}$ & $\begin{array}{c}\mathrm{D} \\
(\mathrm{nm})\end{array}$ & $\begin{array}{r}\mathbf{R} \\
(\mathbf{n m}) \\
\end{array}$ & $\begin{array}{r}\sigma_{\mathrm{R}} \\
(\mathrm{nm}) \\
\end{array}$ & $\begin{array}{r}\Delta \mathbf{R} \\
(\mathbf{n m}) \\
\end{array}$ & ncore & $\mathbf{\eta}_{\text {shell }}$ \\
\hline$P_{1} R_{1} C$ & & & & & & & & \\
\hline (1) & 0.37 & 0.10 & 3.3 & 5.7 & 0.1 & 0.45 & $2.4 \times 10^{-8}$ & $7.5 \times 10^{-7}$ \\
\hline (2) & 0.39 & 0.10 & 3.0 & 5.7 & 0.3 & 0.37 & $1.6 \times 10^{-8}$ & $1.4 \times 10^{-7}$ \\
\hline (3) & 0.43 & 0.14 & 2.9 & 6.0 & 0.5 & 0.37 & $1.9 \times 10^{-8}$ & $2.2 \times 10^{-7}$ \\
\hline (4) & 0.45 & 0.01 & 2.6 & 8.5 & 0.7 & 0.60 & $8.4 \times 10^{-9}$ & $6.5 \times 10^{-8}$ \\
\hline (5) & 0.50 & 0.10 & 2.4 & 20.3 & 0.8 & 0.81 & $2.3 \times 10^{-9}$ & $7.9 \times 10^{-9}$ \\
\hline $\mathbf{P}_{2} \mathbf{R}_{2} \mathbf{C}$ & & & & & & & & \\
\hline (1) & 0.25 & 0.13 & 2.7 & 8.9 & 0.2 & 0.58 & $8.8 \times 10^{-9}$ & $1.6 \times 10^{-16}$ \\
\hline (2) & 0.26 & 0.09 & 2.5 & 9.2 & 0.4 & 0.58 & $1.2 \times 10^{-9}$ & $4.7 \times 10^{-16}$ \\
\hline (3) & 0.24 & 0.02 & 2.5 & 10.2 & 0.2 & 0.52 & $2.1 \times 10^{-9}$ & $1.2 \times 10^{-16}$ \\
\hline (4) & 0.31 & 0.15 & 2.2 & 14.4 & 0.4 & 0.58 & $4.1 \times 10^{-9}$ & $1.6 \times 10^{-16}$ \\
\hline (5) & 0.40 & 0.07 & 2.0 & 26.1 & 0.6 & 0.85 & $2.1 \times 10^{-9}$ & $4.6 \times 10^{-9}$ \\
\hline
\end{tabular}

* The cylinder length (L) was fixed at $100 \mathrm{~nm}$.

The TEM and SAXS data confirm differences in the self-assembly process depending on the solvent. It was considered when analyzing the catalytic performance of the lipopeptides in aldol reactions, using $p$-nitrobenzaldehyde and cyclohexanone. The reactions were performed at room temperature for three days, varying the catalyst amount (5 $\mathrm{mol} \%$ and $20 \mathrm{~mol} \%$ ), for both solvent conditions: water or cyclohexanone/water mixtures, at native $\mathrm{pH}$. The results are schemed in Figure 8, and Table S1 gives more detailed information. The NMR spectra are presented in Figure S8.

Considering the bar graphs in Figure 8, the reaction with 5 mol\% of catalyst $\mathbf{P}_{\mathbf{1}} \mathbf{R}_{\mathbf{1}} \mathbf{W} \mathbf{5}$ (Entry 5 in Table S1) represents the best efficiency of all results performed, achieving the highest conversion (almost $95 \%$ ) and excellent diastereoselectivity (93:7) for the anti aldol product. At the same catalyst amount, for the systems $\mathbf{P}_{\mathbf{1}} \mathbf{R}_{\mathbf{1}} \mathbf{W}$ (1-5) and $\mathbf{P}_{\mathbf{2}} \mathbf{R}_{\mathbf{2}} \mathbf{W}$ (1-5), an enhancement of the conversion was observed with the increase of $\mathrm{PRW}\left(\mathrm{C}_{18} \mathrm{H}_{37}\right)$ and PRW $\left(\mathrm{C}_{18} \mathrm{H}_{37}\right)_{2}$ content, respectively, which can be associated with the packing factor increase, due to the presence of smaller particles, showed previously by SAXS and TEM 
(see Table 1 and Figures 4 and 5). This effect was also observed for a short proline-peptide studied by our group, ${ }^{[28]}$ that produced more compact systems, which promoted an increase of the aldol reaction efficiency because of the easier interaction between the reagents and the catalyst surface, aiding the enamine transition state formation and decreasing its reaction energy barrier.

Increasing the catalyst amount to $20 \mathrm{~mol} \%$, a slight enhancement of the conversion for the systems $\mathbf{P}_{\mathbf{1}} \mathbf{R}_{\mathbf{1}} \mathbf{W}$ (1-4) and $\mathbf{P}_{\mathbf{2}} \mathbf{R}_{\mathbf{2}} \mathbf{W}$ (1-3) was observed, and a decrease of this parameter for samples $\mathbf{P}_{1} \mathbf{R}_{\mathbf{1}} \mathbf{W} 5$ and $\mathbf{P}_{\mathbf{2}} \mathbf{R}_{\mathbf{2}} \mathbf{W}$ (4-5), with a slight reduction of the stereoselectivity. However, the reactions in water excess presented a considerable increase in their conversion, with high diastereoselectivity, suggesting that water favours the substrates approaching, optimizing the catalysts, and enhancing their efficiency.

To investigate whether water content influences the aldol reaction products, the reactions were performed in excess water, using the same lipopeptide catalyst concentrations as for the cyclohexanone/water mixtures. In this case, a considerable decrease in the conversion was verified, mainly for the systems $\mathbf{P}_{\mathbf{2}} \mathbf{R}_{\mathbf{2}} \mathbf{C}$ (1-5), but with similar diastereoselectivity to the systems $\mathbf{P}_{\mathbf{1}} \mathbf{R}_{\mathbf{1}} \mathbf{W}$ (1-5) and $\mathbf{P}_{\mathbf{2}} \mathbf{R}_{\mathbf{2}} \mathbf{W}$ (1-5). Comparing the results from Figure 8 and Table S1, it can be concluded that the reactions take place in the hydrophilic region, as more than $80 \%$ of the solvent corresponds to the cyclohexanone. Still, in $\mathbf{P}_{\mathbf{1}} \mathbf{R}_{\mathbf{1}} \mathbf{C}$ (1-5) and $\mathbf{P}_{\mathbf{2}} \mathbf{R}_{\mathbf{2}} \mathbf{C}(\mathbf{1 - 5})$ this part was constrained in the core so that the reagent attack at the catalyst surface is more difficult, consequently lowering the conversion. The behavior of these systems is similar to another amphiphilic peptide studied by our group that also showed micellar self-assembly, and enhanced catalytic efficiency in an aqueous environment. ${ }^{[27]}$ 

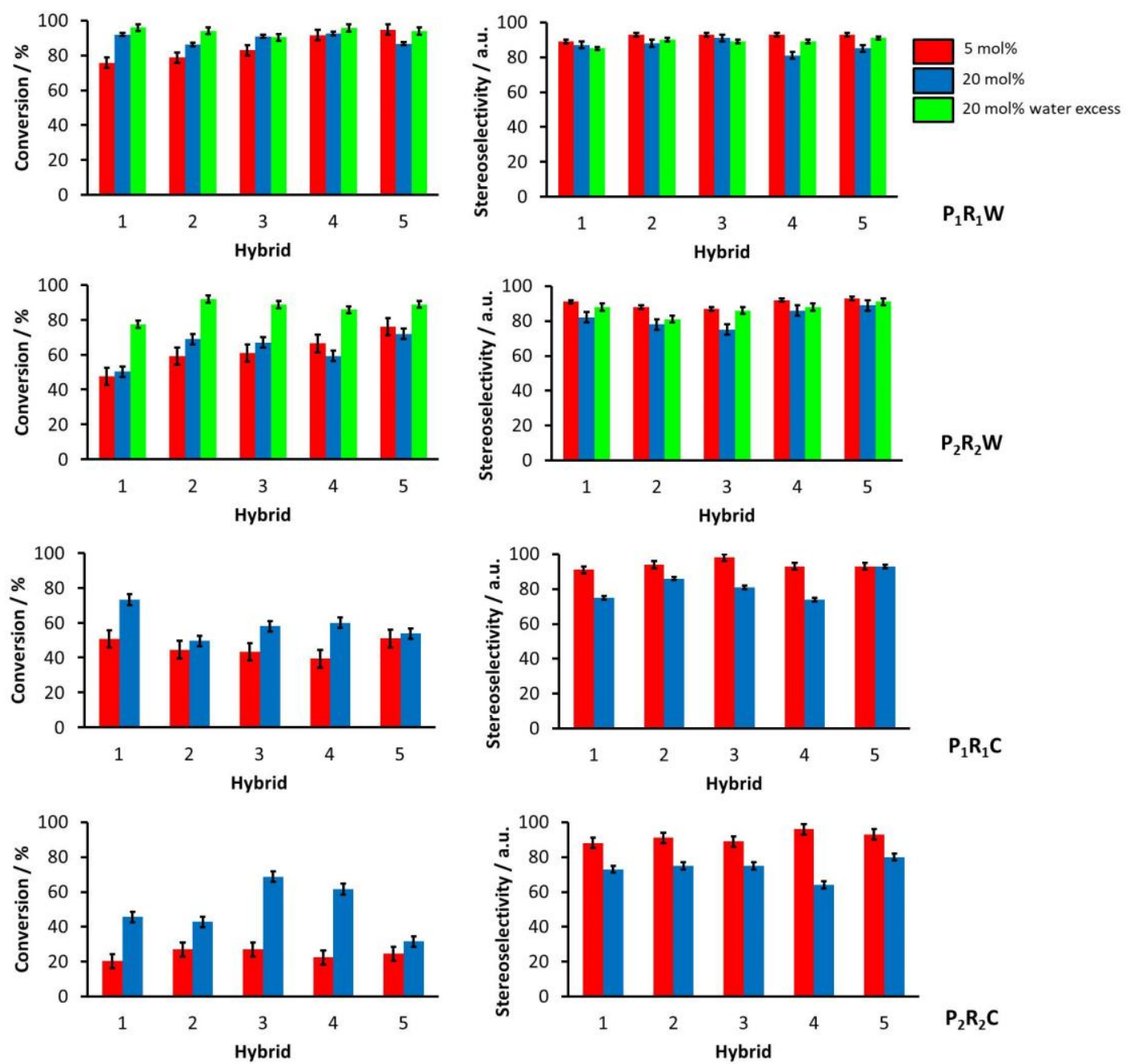

Figure 8. Results from aldol reactions between $p$-nitrobenzaldehyde and cyclohexanone catalyzed by the lipopeptide mixtures. Left: conversion, Right: stereoselectivity. The colored bars represent the catalyst concentration: red (5 mol\%), blue (20 mol\%), and green (20 mol\% with water excess).

\section{CONCLUSIONS}

We have compared the self-assembly process of four new lipopeptide compounds containing one or two amphiphilic tails, in the presence and absence of $\mathrm{N}$-terminal proline residues. The obtained complexes, and their mixtures, were evaluated as catalysts for enantioselective aldol reactions in water and cyclohexanone/water solutions. These materials exhibit similar $c a c$ values of $\sim 4.0 \times 10^{-4} \mathrm{wt} \%$ since that volume occupied by the lipidic part of the molecule does not change so much. It also seems that the aggregation process is governed mainly by the RWG peptide sequence. CD spectra reveal some $\beta$-sheet secondary structure, with a contribution even from $\pi$-stacking of tryptophan residues. TEM reveals nanosheet structures for most systems except $\mathbf{P}_{\mathbf{1}} \mathbf{R}_{\mathbf{1}} \mathbf{W}$ (4-5), which form spherical micelles. The difference in the shape of the nanostructures is presumably related to the 
surfactant packing parameters. The di-alkyl lipopeptides have similar cross-sectional areas of the lipid chains and the peptide, forming layered structures. In contrast, the monoalkyl lipid chains PRWG $\left(\mathrm{C}_{18} \mathrm{H}_{37}\right)$ and its mixtures, containing the highest content of this lipopeptide, form spherical micelles with a core of hydrophobic segments surrounded by a hydrophilic peptide corona. Remarkably, micellar aggregates do not grow in the absence of proline in their network chains. It is likely to be due to the presence of terminal charges on the arginine residues in $\mathrm{RWG}\left(\mathrm{C}_{18} \mathrm{H}_{37}\right)$, which due to electrostatic repulsion, prohibits packing of the peptide "headgroups" into spherical micelles. Instead, bilayer structures are again stabilized because charge effects enhance the peptide-surface interactions. The influence of chains' number on molecular packing of these lipopeptides is consistent with prior reports. ${ }^{[51]} \mathrm{We}$ are not aware of prior studies of the self-assembly or bioactivity of mixed mono- and di-alkyl functionalized peptides.

SAXS consistently confirmed the bilayer or spherical micelle morphology imaged by TEM. The bilayer thickness is 3-4 $\mathrm{nm}$, which is consistent with a highly interdigitated bilayer structure. The length of the molecules is estimated to be approximately $3 \times 0.32 \mathrm{~nm}$ $+18 \times 0.11 \mathrm{~nm}=2.4 \mathrm{~nm}$ for the RWG lipopeptides $(2.7 \mathrm{~nm}$ for the PRWG ones), where the peptide length is based on a parallel $\beta$-sheet structure. ${ }^{[52]}$ The spherical micelle radius ranges from $2.6 \mathrm{~nm}$ to $4.0 \mathrm{~nm}$, again consistent with the estimated molecular length. Systems $\mathbf{P}_{\mathbf{1}} \mathbf{R}_{\mathbf{1}} \mathbf{W}$ (1-5) presented higher packing factor, with smaller particles as the proline-lipopeptide content was enhanced, while the systems $\mathbf{P}_{\mathbf{2}} \mathbf{R}_{\mathbf{2}} \mathbf{W}$ (1-5) remained with similar particle size.

The assembly of the lipopeptides in the mixed organic/aqueous solvent used for the model aldol reaction studies led to cluster aggregates (with a radius of $0.25 \mathrm{~nm}$ to $0.50 \mathrm{~nm}$ ) and some elongated structures (with radius of curvature of $5.7 \mathrm{~nm}$ to $26.1 \mathrm{~nm}$ ). Measurements of catalytic yield and stereoisomerization revealed that the concentration of water in the systems can influence the conversion of the model aldol reactions. Also, it was observed that higher proline content promoted better efficiency for the systems $\mathbf{P}_{\mathbf{1}} \mathbf{R}_{\mathbf{1}} \mathbf{W}$ (15) and $\mathbf{P}_{2} \mathbf{R}_{\mathbf{2}} \mathbf{W}(\mathbf{1 - 5})$, due to the increase of the packing factor, but the opposite was seen for the $\mathbf{P}_{\mathbf{1}} \mathbf{R}_{\mathbf{1}} \mathbf{C}$ (1-5) and $\mathbf{P}_{\mathbf{2}} \mathbf{R}_{\mathbf{2}} \mathbf{C}$ (1-5) samples, as larger structures were formed with increasing proline lipopeptide content.

Considering the influence of polymorphism, we verified that the catalytic efficiency is correlated with the catalyst surface area availability. Comparing the SAXS parameters of each of these systems, it was observed that systems $\mathbf{P}_{\mathbf{1}} \mathbf{R}_{\mathbf{1}} \mathbf{W} \mathbf{4}$ and $\mathbf{P}_{\mathbf{1}} \mathbf{R}_{\mathbf{1}} \mathrm{W} \mathbf{5}$ show the best activity of all samples, and they are characterized by small micelles, which have a high 
surface area availability. For nanotape structures, the conversion efficiency is higher for the systems which contain less thick bilayers $\left(\mathbf{P}_{\mathbf{1}} \mathbf{R}_{\mathbf{1}} \mathbf{W} \mathbf{1 - 3}\right)$ when compared with $\left(\mathbf{P}_{\mathbf{2}} \mathbf{R}_{\mathbf{2}} \mathbf{W}\right.$ 1-5) samples. The proline availability is another factor that has to be considered since it can occupy distinct positions or conformations in the self-assembled structures, and consequently, different reactivity profiles. Furthermore, the effect of phase transfer is another important factor in the enhancement of stereoselectivity in aldol coupling reactions, and this will be important above the $c a c$ of the peptides. Measurements of catalytic yield and selectivity revealed that the concentration of water in the systems influences the aldol condensation product formation.

In summary, our results show that mixing mono- and di-alkyl lipopeptides is a valuable method to tune self-assembly and to control biocatalytic activity.

\section{SUPPORTING INFORMATION SUMMARY}

Additional characterization data are provided in supporting information.

\section{CONFLICT OF INTEREST}

The authors declare no competing financial interests.

\section{ACKNOWLEDGEMENTS}

This work was supported by FAPESP (grant no. 2017/02317-2) and CNPq (grant no. 302923/2015-2). INCT in Bioanalytics (FAPESP grant no. 2014/50867-3 and CNPq grant no. 465389/2014-7) is kindly acknowledged for the grants. J.N.B.D.P. acknowledges FAPESP (project number 2015/20446-9 and 2018/12535-0) for a doctoral fellowship and the research internship abroad program (BEPE). I.W.H. thanks EPSRC for the award of a Platform Grant (EP/L020599/1). We thank Diamond for the award of beamtime on beamline B21 (SM21470-2 and SM22925-1), and Valeria Castelletto for assistance during the beamtime sessions. Special thanks to Jani Seitsonen and Janne Ruokolainen (Aalto University, Finland) for the cryo-TEM images. The authors are grateful for access to the Chemical Analysis Facility at the University of Reading. 


\section{REFERENCES}

1. I. W. Hamley, Chem. Rev., 2012, 112, 5147-5192.

2. J. Geng, K. Qu, J. Ren and X. Qu, Mol. BioSys., 2010, 6, 2389-2391.

3. T. Takahashi and H. Mihara, Acc. Chem. Res., 2008, 41, 1309-1318.

4. G. Wei, Z. Su, N. P. Reynolds, P. Arosio, I. W. Hamley, E. Gazit and R. Mezzenga, Chem. Soc. Rev., 2017, 46, 4661-4708.

5. H. Cui, M. J. Webber and S. I. Stupp, Biopolymers, 2010, 94, 1-18.

6. I. W. Hamley, Soft Matter, 2011, 7, 4122-4138.

7. I. W. Hamley, Chem. Commun., 2015, 51, 8574-8583.

8. C. J. C. Edwards-Gayle and I. W. Hamley, Org. Biomol. Chem., 2017, 15, 5867-5876.

9. R. C. Bianchi, E. R. Silva, L. H. Dall'Antonia, F. F. Ferreira and W. A. Alves, Langmuir, 2014, 30, 11464-11473.

10. R. F. Silva, D. R. Araújo, E. R. Silva, R. A. Ando and W. A. Alves, Langmuir, 2013, 29, 10205-10212.

11. E. R. Silva, G. Cooney, I. W. Hamley, W. A. Alves, S. Lee, B. F. O'Connor, M. Reza, J. Ruokolainen and D. Walls, Soft Matter, 2016, 12, 9158-9169.

12. Y. Cui, S. N. Kim, R. R. Naik and M. C. McAlpine, Acc. Chem. Res., 2012, 45, 696-704.

13. S. Brown, M. Sarikaya and E. Johnson, J.Mol. Biol., 2000, 299, 725-735.

14. R. R. Naik, S. J. Stringer, G. Agarwal, S. E. Jones and M. O. Stone, Nat. Mater., 2002, 1, 169-172.

15. H. Cui, M. J. Webber and S.I. Stupp, Pept. Sci., 2010, 94, 1-18.

16. E. R. Silva, E. Listik, S. W. Han, W. A. Alves, B. M. Soares, M. Reza, J. Ruokolainen and I. W. Hamley, Biophys. Chem., 2018, 233,1-12.

17. D. W. P. M. Löwik and J. C. M. van Hest, Chem.Soc. Rev., 2004, 33, 234-245.

18. J. B. Matson, R. H. Zha and S. I. Stupp, Curr. Opin. Solid State Mater. Sci., 2011, 15, 225235.

19. A. Dehsorkhi, V. Castelletto and I. W. Hamley, J. Pept. Sci., 2014, 20, 453-467. 
20. F. Rodríguez-Llansola, J. F. Miravet and B. Escuder, Chem.: Eur. J., 2010, 16, 8480-8486.

21. F. Rodríguez-Llansola, B. Escuder and J.F. Miravet, J. Am. Chem. Soc., 2009, 131, 1147811484.

22. Y. Lou, Q. Zhang, H. Wang and Y. Wang, J. Catal., 2007, 250, 365-368.

23. Y. Q. Fu, Y. J. An, W. M. Liu, Z. C. Li, G. Zhang and J. C. Tao, Catal. Lett., 2008, 124, $397-404$.

24. Y. Hayashi, S. Aratake, T. Okano, J. Takahashi, T. Sumiya and M. Shoji, Angew. Chem. Int. Ed., 2006, 45, 5527-5529.

25. L. Zhong, Q. Gao, J. Gao, J. Xiao and C. Li, J. Catal., 2007, 250, 360-364.

26. F. Rodríguez-Llansola, B. Scuder, I. W. Hamley, W. Hayes and J. F. Miravet, Soft Matter, $2012,8,8865-8872$.

27. B. M. Soares, A. M. Aguilar, E. R. Silva, M. D. Coutinho-Neto, I. W. Hamley, M. Reza, J. Ruokolainen and W. A. Alves, Phys. Chem. Chem. Phys., 2017, 19, 1181-1189.

28. J. N. B. D. Pelin, Barbara B. Gerbelli, Bruna M. Soares, Andrea M. Aguilar and Wendel A. Alves, Catal. Sci. Technol., 2019, 9, 4304-4313.

29. J. G. Hernandez and E. Juaristi, Chem. Commun., 2012, 48, 5396-5409.

30. M. Hiersemann, Synthesis, 2007, 2007, 483-483.

31. B. List, R. A. Lerner and C. F. Barbas, J. Am. Chem. Soc., 2000, 122, 2395-2396.

32. A. Kumar, Manika Dewan, Arnab De, Amit Saxena, Swati Aerry and Subho Mozumdar, RSC $A d v ., 2013,3,603-607$.

33. P. Melchiorre, M. Marigo, A. Carlone and G. Bartoli, Angew. Chem. Internat. Ed., 2008, $47,6138-6171$.

34. S. Bertelsen and K. A. Jørgensen, Chem. Soc. Rev., 2009, 38, 2178-2189.

35. A. Dondoni and A. Massi, Angew. Chem. Internat. Ed., 2008, 47, 4638-4660.

36. B. List, Acc. Chem. Res., 2004, 37, 548-557.

37. M. Raj and V. K. Singh, Chem. Commun., 2009, 44, 6687-6703.

38. C. Pidathala, L. Hoang, N. Vignola and B. List, Angew. Chem. Int. Ed., 2003, 42, 27852788. 
39. F. Rodríguez-Llansola, J. F. Miravet and B. Escuder, Chem. Commun., 2009, 47, 73037305.

40. J. Huang, X. Zhang and D.W. Armstrong, Angew. Chem. Int. Ed., 2007, 46, 9073-9077.

41. A. Hawe, M. Sutter and W. Jiskoot, Pharm. Res., 2008, 25, 1487-1499.

42. J. A. Hutchinson, I. W. Hamley, J. Torras, C. Alemán, J. Seitsonen and J. Ruokolainen, J. Phys. Chem. B, 2019, 123, 614-621.

43. D. Diana, C. Di Salvo, V. Celentano, L. De Rosa, A. Romanelli, R. Fattorusso and L. D. D'Andrea, Org. Biomol. Chem., 2018, 16, 787-795.

44. A. R.Viguera, J. L. R. Arrondo, A. Musacchio, M. Saraste and L. Serrano, Biochemistry, 1994, 33, 10925-10933.

45. S. Conti, G. Radicioni, T. Ciociola, R. Longhi, L. Polonelli, R. Gatti, T. Cabras, I. Messana, M. Catagnola and A. Vitali, Biochim. Biophys. Acta, Biomembr., 2013, 1828, 1066-1074.

46. J. L. Lopes, A. J. Miles, L. Whitmore and B. A. Wallace, Protein Sci, 2014, 23, 1765-1772.

47. I. Bressler, J. Kohlbrecher and A.F. Thünemann, J. Appl. Crystallogr., 2015, 48, 15871598.

48. G. Pabst, M. Rappolt, H. Amenitsch and P. Laggner, Phys. Rev. E, 2000, 62, 4000-4009.

49. V. Castelletto, R. M. Gouveia, C. J. Connon and I. W. Hamley, Faraday Discussions, 2013, $166,381-397$.

50. V. Castelletto and I. W. Hamley, Methods to Characterize the Nanostructure and Molecular Organization of Amphiphilic Peptide Assemblies. In Peptide Self-Assembly: Methods And Protocols. Human Press Inc: Totowa, 2018. 1777, 3-21.

51. I. W. Hamley, S. Kirkham, A. Dehsorkhi, V. Castelletto, M. Reza and J. Ruokolainen, Chem. Commun., 2014, 50, 15948-15951.

52. T. E. Creighton, Proteins: Structures and Molecular Properties. New York : W.H. Freeman, 1993, $2^{\text {nd }}$ Ed., p.507. 
